\title{
CONSIDERACIONES SOBRE LA FORMACIÓN DE PALABRAS EN ESPAÑOL
}

\author{
Juan Manuel García Platero \\ (Universidad de Sevilla)
}

\begin{abstract}
RESUMEN
When analysing word formation processes, it should be born in mind that they are one of the central aspects of the energeia or potentiality of language. For this reason, corpus-based analyses are needed to reach conclusive results. The detailed observation of the cmpirical data leads to the concept of a gradient or cline of word formation processes more than to clear-cut categories. Thus, affixational and compositional neological processes should be thought of as part of a continuum rather than separate entities.
\end{abstract}

No cabe duda del interés que ha despertado el estudio de los diversos procedimientos de formación de palabras, si nos fijamos en los numerosos trabajos publicados hasta ahora', pese a que la mayoría de ellos, independientemente de que sus orientaciones sean de tipo funcional ${ }^{2} o$

1 Para la bibliografía véanse Ignacio Bosque y José Antonio Mayoral, «Formación de palabras. Ensayo bibliográlico», Cuadernos bibiliográficos, 38, 1979, págs. 245-275; Franz Rainer, «Setenta años (1921-1990) de investigación en la formación de palabras del español moderno: bibliografía crítica selectivals, en Soledad Varela Ortega (ed.), La formación de palabras, Madrid, Taurus, 1993, págs. 30-70; David Pharies, Bibliography of Latin and Ibero-Romance. Suffixation, Madison, The Hispanic Seminary of Medicval Studies, Lid., 1994, y Joaquín García-Medall, Casi un siglo de formación de palabras del español (1900-1994). Guía bibliográfica, Cuadernos de Filología, Anejo XIII, Valencia, Facultad de Filología, 1995.

Clr., entre otros, los trabajos de Leonard Bloomfield, Langage, Nueva York, Holt, Rinehart \& Winston, 1933 (cito por la traducción española: Lenguaje, Lima, Universidad Nacional Mayor de San Marcos, 1964, especialmente págs. 247-299); Pierre Guiraud, Structures étymologiques du lexique français, París, Larousse, 1967; André Martinet, Elementos de lingüística general, Madrid, Gredos, 1970; Eugenio Coseriu, «Introducción al estudio estructural del léxico», en Principios de senaintica estructural, Madrid, Gredos, 1977, págs. 87-142, «La formación de palabras desde el punto de vista del contenido. (A propósito del tipo «coupe-papier»)», en Gramática, senúntica, universales. Esitudios de lingüistica funcional, Madrid, Gredos, 1978, págs. 239-264; y Thierry Debaty-Luca, Théorie 
generativista ${ }^{3}$ (no hay que olvidar que ambas son necesarias para el conocimiento lexicográfico ${ }^{4}$ ), se centran en aspectos parciales, siempre desde una visión descriptiva ${ }^{5}$. Aunque en nuestro país la atención sobre la formación de nuevos

fonctionnelle de la suffixation, Liège, Blibliothèque de la Faculté de Philosophie et Lettres de la Université de Liège, 1985.

Véanse los estudios de Jean Dubois (Étude sur la dérivation suffixale en français moderne el contemporcin, París, Larousse, 1962; «La dérivation en linguistique descriptive et en linguistique transformationnelle», Travalux de linguistique et de littérature, VI, 1, 1968, págs. 27-53), Anne Zribi ( LLa créativité lexicale: Traitement de quelques préfixes dans une grammaire générative du français», $L e$ Françuis Moderne, XLI, 1, 1973, págs. 58-67), Jacqueline Bastuji («Aspects de la néologie sémantique», Lamgages, 36, 1974, págs. 6-19, especialmente págs. 12-14), Louis Guilbert («De la formation des unités lexicales», en Introduction atu Grand Larousse de la langue Française, I, págs. IX-XXXI, París, Larousse, 1971; «Grammaire générative et néologie lexicale», Langages, 36 y La créativité lexicale, Paris, Larousse, 1975); Mark Aronoff (Word Formation in Generative Grammar, Massachusetts and London, England, The MIT Press, 1976), Hernán Urrutia Cárdenas («El método generativo en la alijación lexicogenésica», Español Actual, 32, 1978, págs. 7-10 y «La formación de palabras en la linguística generativa natural», Philologia Hispaniensia in honorem Manuel Alvar, II, Madrid, Gredos, 1985, págs. 631-636), Maurizio Dardano (La formazione delle parolle nell'italiano di oggi, Roma, Bulzoni Editori, 1978), Germán Gil Jiménez ( $« E l$ funcionalismo de E. Coseriu y la hipótesis lexicalista chomskyana en algunos derivados nominales», Analecta Malacitana, VI, 1983, págs. 389-397) y Sergio Scalise (Morfología derivativa, Madrid, Alianza, 1987). En cuanto a la sufijación del español cfr. los taabajos de Eugenio Martínez Celdrán (Sufijos nominalizadores del español con especial atención a su morfonologíal, Barcelona, Ediciones de la Universidad, 1975, especialmente págs. 24-40), Soledad Varela Ortega («En torno a la morfología derivativa», Español Actual, 37-38, 1980, págs. 1-6 y Funtamentos de morfología, Madrid, Síntesis, 1990) y Agustín Vera Luján (Aspectos sintácticosemánticos en la sufijación, reimpr., Murcia, Ediciones de la Universidad, 1992). Sobre la composición de palabras, la visión generativista en el estudio de la formación de nuevos vocablos ya aparece formulada por Arsène Darmesteter al considerar al vocablo compuesto o prefijado como formación proposicional en su Traité de la formation des mots composés dans la langue française comparée aux autres langues romanes et au latin, París, Librairie A. Franck, 1875 (reedición, París, Librairie Honoré Champion, éditeur, 1967, pág. 5: «Un mot est une proposition en raccourci et cela est si vrai que la question de la place du déterminant par rapport au déterminé se ramène au fond à la question de la place de l'attribut dans la phrase»). Cfr., además, los trabajos de Anca Giurescu, «El método transformacional en el análisis de los nombres compuestos del español moderno», Revue Roumaine de Linguistique, XXVII, 3, 1972, págs. 407-414 y Les mots composés dans les langues romanes, La Haya-París, Mouton, 1975.

Cfr. Stefan Ettinger, «Formación de palabras y fraseología en la lexicografía», en G. Haensch, L. Wolf, S. Ettinger y R. Werner, La lexicografía. De la lingitística teórica a la lexicografía práctica, Madrid, Gredos, 1982, págs. 233-258; Felipe Gómez Solís, «Acerca de un tipo de composición nominal en español (cstudio lexicográfico)», Estudios Humanísticos Filología, 9, 1987, págs. 31-52, y Jesús Pena, «Formación de palabras, gramática y diccionario», Revista de Lexicografía, 1, 1994-1995, págs. $163-181$.

Véase Soledad Varela Ortega, «Líneas de investigación en la teoría morfológica», en Soledad Varela Ortega (ed.), La fornación de palabras, Madrid, Taurus, 1993, págs. 13-29, especialmente pág. 21. Esta misma autora incluye una serie de rasgos distinguidores que comparte la investigación de la lormación de nuevas unidades léxicas en los últimos cincuenta años: «a) Clara delimitación de lo sincrónico frente a lo diacrónico. b) Abandono de las disquisiones etimológicas en los trabajos sobre la mortología del español moderno. c) Identificación de los morfemas afijales operativos en el español moderno. d) Interés por los aspectos semánticos y morfofonológicos de la palabra derivada o compuesta. e) Especial atención a los neologismos de variado signo, con énfasis en la motivación semántica $-y$ pragmáticat- de la creación léxica. f) Estudio de la polisemia afijal y de la especialización de afijos 
vocablos ya ocupaba algunas páginas en la Gramática de Nebrija ${ }^{6}$, habría que esperar hasta 1920 para encontrarnos con el estudio global de José Alemany Bolufer $^{7}$. Y pese a que muchas de sus apreciaciones están superadas, lo cierto es que hasta hace poco tiempo era la única obra de referencia obligada ${ }^{8}$.

Los diversos procedimientos de formación de palabras, como indicaba Eugenio Coseriu", deben situarse dentro de la virtualidad del sistema y no en la norma - pues el sistema coincide con las técnicas abiertas que no niegan la posibilidad de actuación en el discurso, y aquí se sitúan los constituyentes lexicogenésicos antepuestos o pospuestos que son elementos de verdadera «energeia», junto con los que representan meros resultados que pueden devenir en virtualidad"1"....

Se ha dicho más de una vez, y no sin razón, que los distintos procedimientos de formación de nuevas unidades léxicas empleados en nuestro idioma tienen como elemento común la libertad de procedimiento, frente a las otras lenguas románicas:

concurrentes. g) Contrastación - con recurso a la traducción- entre lenguas emparentadas como un medio de sacar a la luz maticcs semánticos y estilísticos del tipo morfológico considerado».

Grankílica de la lengua castellana (Salamanca, 1492). Edición de Antonio Quilis, Madrid, Instituto de Cooperación Iberoamericana, 1992. Véanse, en este sentido, los trabajos de Elisabeth Beniers Jacobs, «La morfología derivacional en la Gramática castellana de Nebrija», Antario de Letras, XXXI, 1993, págs. 31-51 y Margarita Lliteras, «La doctrina de Nebrija sobre la formación de palabras», en Ralph Penny (ed.), Actas del Priner Congreso anglo-hispano, I. Lingiiística, Madrid, Castalia, 1993, págs. 99-111

Tratado de la formación de palabras de la lengua castellana. La derivación y la composición. Estudio de los sufijos y los prefijos empleados en tena y otra, Madrid, Librería de Victoriano Suárez, 1920.

En la actualidad, no escasean visiones globales como la de Ricardo A. Narvácz, An Outline of Spanish Morphology. Forntation of Words, Inflectional and Derivational, St. Paul, Minnesota, EMC Corporation, 1970. Otro análisis de conjunto es el de Mervyn Franc Lang, Spanish word formation. Productive derivational norphology in the modern lexis, Londres-Nueva York, Routledge, 1990 [Versión española: Formación de palabras en español. Morfologia derivativa productiva en el léxico moderno, Madrid, Cátcdra, 1992], que incorpora, junto con los constituyentes lexicogenésicos, fenómenos como el abreviamiento y la abreviación, y basa parte de sus conclusiones en un corpus literario-periodístico. Véanse también Manuel Alvar Ezquerra, La formación de palabras en español, Madrid, Arco/Libros, $3^{a}$ ed., 1996, y José Alberto Miranda, La formación de palabras en español, Salamanca, Ediciones del Colegio de España, 1994. De gran interés son las aportaciones de lorgu lordan y María Manoliu, Manual de lingiüstica románica, II, Madrid, Gredos, 1972 y Manuel Alvar y Bernard Potticr (Morfologia histórica del español, Madrid, Gredos, 1983). Asimismo, y pese a su brevedad, es muy ilustrativo el trabajo de Fernando González Ollé y Manuel Casado Velarde «Spanisch: Wortbildunglchre. Formación de palabras», en G. Holtus, M. Metzeltin y C. Schmitt (coords.), Lexikon der romenistischen Linguistik (LRL), VI, 1, Tubinga, Max Niemeyer, 1992, págs. 91-109. Finalmente, pese a que se ciñe únicamente a la lengua catalana, conviene destacar el reciente trabajo de $\mathrm{M}^{\mathrm{a}}$ Teresa Cabré, $\Lambda$ l'entorn de la paraula, 2 vols., Valencia, Universidad, 1994.

9 Lecciones de lingüística general, Madrid, Gredos, 1986, pág. 324.

10) Manucl Álvarez García, Lexico-génesis en español: los morfemas facultativos, Sevilla, Publicaciones de la Universidad, 1979, págs. 109-110. 
La primera particularidad que se impone a un observador, aunque no sea muy atento, es que el español se mueve mucho más libremente que otras lenguas románicas, por ejemplo el francés o el italiano, en el dominio de la formación de palabras ${ }^{\mathrm{H}}$.

Esta evidente capacidad del español para crear nuevas unidades sin especiales imposiciones de tipo analítico ${ }^{12}$ puede dar lugar a múltiples puntos de vista. En principio, habría que delimitar el propio concepto de formación de palabras, ya que se puede adoptar una posición más o menos estricta ${ }^{13}$. En un sentido amplio, se podría tener en cuenta la inclusión en este campo de estudio de todos los mecanismos utilizados para crear nuevos significantes ante realidades inéditas, que hasta el momento no han encontrado su expresión linguiística. Desde esta perspectiva, habría que recordar las cuatro «vías lexicogenésicas» expuestas por Pierre Guiraud ${ }^{14}$ : la composición y derivación, el cambio de sentido, el préstamo y la onomatopeya. Por el contrario, y desde una visión más restringida, podríamos ceñinos a la formación de nuevos vocablos a partir de otros términos preexistentes, por lo que habría que referirse únicamente a las creaciones compositivas y derivativas, frente a procedimientos que obedecen a una motivación de carácter fónico o semántico. En este sentido, se puede afirmar que la formación de palabras puede incrementar la motivación del significante frente al préstamo, ya que este, al menos en un primer momento, «arricchisce la lingua con singole unità lessicali, non con serie di parole tra loro correlate e motivate» ${ }^{15}$.

No cabe duda de que hay que rechazar demasiadas generalizaciones al estudiar los diversos procedimientos de creación léxica, como puede ser la delimitación entre los procedimientos compositivos y los derivativos, por más que algunos autores establezcan que las diferencias están suficientemente claras.

1 lourgu lordan, «Observaciones sobre la formación de palabras en español», Actas del III Congreso Internacional de Hispanistas, México, El Colegio de México, 1970, págs. 443-451. Tomo la cila de la pág. 443.

12 Albert Belot (L'espagnol aujourd'hui. Aspects de la créativité lexicale en espagnol contenporain, Perpiñán, Castillet, 1987, pág. 22) se refirió, al tratar el uso de los prefijos en español, a esta tendencia sintética de nuestra lengua frente al carácter analítico francés: «Même si l'on ne dispose pas de statistiques concernant la productivité compararée des prélixes en français et en espagnol, un premier élément de réponse est fourni par les nouvelles création de l'espagnol que nous ne pouvons rendre qu'à l'aide d'un adverbe traditionnel ou d'une périphrase: 'Brasil tricampeón del mundo' (triple champion); 'Los italianos subcampeones' (vice-champions); desconvocar la huelga, 'annuler l'ordre de grève'; un polideportivo, 'un complexe sportif'; la minipantalla, 'le petit écran'; sobremedicarse, 'prendre trop de médicaments'. La confrontation de ces énoncés en l'une et l'autre langue montre la supćriorité des hispanismes sur le plan de l'expressivité et de l'économie syntaxique, même si le prix à paycr est un allogement des lexèmes».

1.3 Crr. M* Paz Ramos, «Recursos del español para la creación de palabras», en Esperanza R. Alcaide, Ma del Mar Ramos, Francisco J. Salguero (eds.), Estudios lingüisticos en torno a la palabra, Sevilla, Universidad, 1993, págs. 161-179, especialmente pág. 162.

14. Structures étynulogiques du lexique français, op. cit., pág. 24.

15 Maurizio Dardano, op. cit., pág. 5. 
No cntrarcmos en el análisis de las diversas denominaciones de estos conslituyentes, ya que el criterio cuantitativo será el que fije su inclusión dentro del ámbito de la derivación o de la composición ${ }^{16}$, independientemente de cualquier discusión terminológica, pues ambos procedimientos de creación léxica no están tan delimitados:

Entrc derivación y composición no existe, desde un punto de vista histórico, un límite preciso. Un sustantivo puede desgastarse poco a poco semánticamente y degradarse hasta convertirse en sufijo. Composición y derivación están, por tanto, la una con respecto a la otra, en una relación de continuidad histórica. La derivación es, por tanto, una composición desgastada y extendida por la analogía ${ }^{17}$.

El mismo criterio de cuantificación puede reflejar el carácter sufijal o compositivo, a juicio de Alba de Diego ${ }^{18}$, de ciertas palabras como «modelo», «clavc», cle., que pudieran gramaticalizarse, si la frecuencia no fuera mayor cuando posecn autonomía propia que cuando son parte de las formaciones sintagmáticas, frente a la de otros constituyentes lexicogenésicos, aunque se pueda percibir la pérdida de significado del segundo término mediante metábasis simplifícadora ${ }^{19}$, semejante a la observada en la prefijación y sufijación de caráter apreciativo, que es, por otra parte, una tendencia habitual (se corrobora por la invariabilidad del vocablo determinante) y no exclusiva de nuestro idioma ${ }^{20}$.

Pese a la teoría que niega que la homocategorización sea un rasgo distinguidor entre la prefijación y la sufijación, hay quien recuerda la frecuente capacidad transpositiva de derivación sufijal («En efecte, les possibilitats de rccalcgorització d'una base lèxica per mitjà de prefixos són extremadament pobres si les comparem amb les que ofereixen els sufixos ${ }^{21}$ ), y niega esta función a las formas prefijales. Así, Mervyn Franc Lang ${ }^{22}$ pone en duda que el cambio

16. No hay que olvidar, sin embargo, la propia conciencia del hablante $y$, por lo tanto, el valor significativo que le conceden a las formaciones híbridas en las que entra un elemento foráneo, como recordó Eugenio de Bustos Tovar («Algunas observaciones sobre la palabra compuesta», RFE, XLIX, págs. 255-274, especialmente págs. 262-264).

17 Walther von Wartburg, Problemas y nétodos de la linguiística, Madrid, CSIC, 1951, pág. 158.

18 «Elementos prefijales y sufijales: ¿derivación o composición?», en Serta Philologia F. Lázaro Carreter, I. Esitudios de lingiḯstica y lengua literaria, Madrid, Cátedra, 1983, págs. 17-21, especialmente pág. 20.

19 Rafael Lapesa, "Tendencias y problemas actuales de la lengua española», en Rafael Lapesa, (coord.), Comunicación y lenguaje, Madrid, Karpos, 1977, págs. 220-223.

20 Nina Catach, «L'intégration graphique des mots nouveaux», en Néologie el lexicologie. Homnlage à Lotuis Guilhert, París, Larousse, 1979, pág 71 observa que «on note aujourd'hui une tendance, dans toute une série de cas, à l'invariabilité du terme déterminant, ou du synthème considéré comme adjectif composé: mots-clef, remèdes-standard, guerres-éclair, lampes témoin, voitures-pie, valcurs or, ćpargne logement, plans épargne-logement, etc.»

$21 \mathrm{M}^{\mathrm{n}}$ Teresa Cabré, A l'entorn de la paraula, op. cit., pág. 70.

22 Op. cit. pág. 222. 
Categorial sea un rasgo característico de los formantes antepuestos, ni siquiera cuando acompaña a las formaciones de verbos denominales: «consideramos que el cambio de categoría gramatical no constituye un rasgo fundamental de la prefijación, sino que se trata de un fenómeno particular de la parasíntesis», por más que no haya que olvidar la presencia en el léxico actual de diversas creaciones adjetivas nominalizadas por elisión de la forma sustantiva, debido a la presencia del constituyente antepuesto. Al mismo tiempo, conviene recordar que no siempre la sufijación presenta un carácter modificativo de la clase gramatical a la que pertenece el vocablo. En este sentido, Silvia Faitelson-Weiser ${ }^{23}$ distingue los sufijos precategorizadores, que sí transforman la categoría gramatical de la base, de los lexicalizadores y no lexicalizadores, a los que les está negada esta función.

La delimitación entre los morfemas flexivos y los sufijales nos obliga a huir de los dogmas ${ }^{24}$. No hay que olvidar la existencia de una serie de rasgos, enumerados por Méndez Dosuna y Carmen Pensado ${ }^{25}$, que expresan las equivalencias entre la formación de diminutivos y la flexión, como puede ser la productividad de estos afijos apreciativos, su transparencia semántica, la ausencia de función transcategorizadora y la tendencia a la pérdida de las reglas de tipo morfofonológico, que reducen la transparencia morfotáctica. Por ello, se puede afirmar, en palabras de Yakov Malkie ${ }^{26}$, que «las conexiones entre la formación de palabras y la flexión son particularmente estrechas», al tratarse de «dos territorios adyacentes que constituyen conjuntamente el reino de la morfología».

El criterio cuantitativo parece marcar diferencias entre los seudoprefijos y los términos que conforman la lexía compuesta ${ }^{27}$, por más que diversos autores

23 «Las funciones sulijjales en español moderno», Revue de Linguistique Romane, 46, 1982, págs. 299-317.

24 Hay dos planteamientos básicos referentes a la consideración de la formación de palabras como parte integrante de la morfología o la lexicología. Tradicionalmente, se suelen incluir los procesos flexivos, derivativos y compositivos dentro del campo de la morfología (cfr. Ángel Manteca AlonsoCortes, Lingiuística general, Madrid, Cátedra, 1987, págs. 111-114 y José Alberto Miranda, op. cit., págs. 46-50). Sin cmbargo, no hay que olvidar el criterio que considera que los procedimientos de formación de nuevas unidades deben pertenecen al ámbito del vocabulario: «Para los lingüistas que incluyen la formación de las palabras en el vocabulario, lo esencial es el resultado, no el medio utilizado para cl enriquecimiento del idioma: con ayuda de sufijos, prefijos y composición se crean palabras nuevas, se agranda el léxico, y de ahí infieren que las nuevas palabras se deben estudiar junto a las antiguas, de las que no se diferencian en nada, pues cumplen los mismos servicios que éstas.» (Jorgu Iordan y María Manoliu, Manual de lingïística románica, op. cit., pág. 9).

25 «How Unnautralis Spanish Víct-ít-or? Infixed Díminutives in Spanish», en Méndez Dosuna y Carmen Pensado (eds.), Naturalist at Drems, Salamanca, Ediciones de la Universidad, 1990, págs. 89-106. Cito por la traducción española, publicada en Varela Oitega [ed.], La fornación de palabras, op. cit., págs. 316-335, especialmente pág. 323.

20 «Genetic Analysis of Word Formation», en Thomas A. Sebeok (ed.), Current Trends in Lingutistics, III, Theoretical Foundations, La Haya, Mouton, 1966, págs. 305-364. (Versión abreviada traducida al español, «El análisis genético de la formación de palabras», en Soledad Varela Ortega [ed.], La formación de palabras, op. cit., págs. 71-115. Tomo la cita de la pág. 75.)

27 Véanse lorgu Iordan y María Manoliu, op. cit., pág. 44 y Vidal Alba de Diego, art. cit., pág. 18. 
los sitúen en el apartado dedicado a la composición. José Alemany ${ }^{28}$, que se refirió a los prefijos en general, los incluye en el apartado dedicado a la composición, al igual que la Academia ${ }^{29}$. Autores como Manuel $\mathrm{Seco}^{30}$, Manuel Alvar y Bernard Pottier ${ }^{31}$ o André Goosse ${ }^{32}$ estudian los prefijos propiamente dichos en el apartado correspondiente a las formas derivadas y tratan los elementos prefijales o sufijales dentro de la composición de vocablos. Por su parte, Iorgu Iordan y María Manoliu ${ }^{33}$ incluyen en el apartado dedicado a la derivación a las formas prefijadas y seudoprefijadas, aunque tienen en cuenta una serie de diferencias entre estos constituyentes que los llevaría a ser indentificados como palabras independientes, pues se distinguen «no tanto por su función cuanto por su origen y por el sentido que confieren a las palabras» ${ }^{34}$. María Teresa Cabré ${ }^{35}$ sitúa estas unidades dentro de los compuestos cultos híbridos, formados por un constituyente de origen grecolatino y una palabra actual. Por otro lado, Mervyn Franc Lang ${ }^{36}$, que reconoce la complejidad de la cuestión, trata de los prelijoides en el capítulo dedicado a la prefijación, aunque no aparecen reflejados en ninguna de las clasificaciones nocionales de los diferentes constituyentes, ya que los incluye en un apartado especial y se refiere a su productividad que «les lleva a extenderse a ámbitos ajenos a su original especialización, y por más que, en algunas ocasiones, reflejen términos de procedencia extranjera, parece recomendable aceplar su adscripción al grupo de los prefijos estándar, particularmente en aquellos casos en que producen series derivativas inequívocamente patrimoniales (telenovela, microsurco, radioyente) $\gg^{37}$. Manuel Alvar Ezquerra ${ }^{38}$ tampoco olvida referirse a la dificultad de incluir estos elementos en uno u otro apartado, aunque los sitúa en la derivación, frente al tradicional carácter compositivo de los prefijos vulgares.

Como hemos visto, si obviamos los criterios cuantitativos — junto con el que se ciñe a la unión del afijo o elemento compositivo con vocablos pertenecientes a las diferentes categorías gramaticales-, es difícil establecer una clasilicación estricta, aunque se distinga entre derivación (mediante los procedimicntos de prefijación y sufijación) y composición, en relación con el carácter recurrente de los formantes lexicogenésicos.

Op. cit., pág. 173.

Grameitica de la lengua castellana, Madrid, Espasa Calpe, 1931, pág. 151, y Esbozo de una nueva gramática de la lengua española, Madrid, Espasa Calpe, 1973, págs. 76-79.

Gramática esencial del español, $2^{\mathrm{a}}$ ed., Madrid, Espasa Calpe, 1991, pág. 216.

Op. cit., págs. $417-418$

La néologie francaise aujourd'hui. Observations et réflexions, París, 1975, págs. 33-36.

Op. cit., págs. 38 y $44-49$.

Jbídem, pág. 38.

A l'entorn de la paraula, op. cit., II, pág. 36.

Op. cit., págs. $237-240$.

lbídem, pág. 240.

La formación de palabras en español, op. cit., págs. 49-50. 
Razones de economía aconseja considerar a los interfijos meras variantes alomórficas de los constituyentes lexicogenésicos pospuestos, como proponen José G. Moreno de $\mathrm{Alba}^{30}$ o Manuel Álvarez García ${ }^{40}$, aunque autores como Fernando Lázaro Carreter ${ }^{41}$ hayan señalado que estos segmentos de palabras no carecen de la significación negada entre otros por Yakov Malkiel ${ }^{42}$ («elemento siempre átono y falto de significado propio, entre el radical y el sufijo de ciertos derivados, por ejemplo, el elemento -ar en hum-ar-eda, polv-ar-eda, palabras que no es lícito descomponer en humar- y polvar-eda por no existir ni haber existido nuncal, que sepamos, las fases intermedias *humar-, "polvar- como formaciones independientes ${ }^{4.3}$ ), Manuel Alvar y Bernard Pottier ${ }^{44}$, Emilio Alarcos ${ }^{4.5}$, Wolfgan Ulrich Dressler ${ }^{46}$ o Ángel Alonso-Cortés Manteca ${ }^{47}$, sobre todo cuando nos referimos a la función de corrección aminoradora presufijal ${ }^{48}$ al darse una especial relación entre el interfijo y los constituyentes lexicogenésicos de apreciación diminutiva ${ }^{49}$, aunque en estos casos habría que hablar de infijación, frente al la interfijación ${ }^{50}$.

Por su parte, Silvia Faitelson-Weiser ${ }^{5 t}$, que utiliza el término «incremento», opina que estas secuencias no son de igual naturaleza, por lo que distingue entre aquellos elementos que protegen la identidad de la base y los que se originan por confusión o se emplean con fines expresivos («más íntimamente relacionados con la sufijación $»^{52}$ ), de los que parecen ser meros «residuos ctimológicos»s sin función específica.

39) «Sobre la formación de palabras en español», Anuario de Letras, 15, 1977, pág. 94.

Op. cit., págs. 34-36.

41 «Consonantes antihiáticas en español», en Homenaje a Antonio Tovar ofrecidos por sus discípulos, colegas y cunigos, Madrid, Gredos, 1972, págs. 253-264 (recogido en Estudios de lingüística, Barcelona, Crílica, 1989, págs. 11-26).

42 «Los interfijos hispánicos. Problema de lingüística histórica y estructural», en Diego Catalán (ed.), Miscelánea Homenaje a André Martinet. Il. Estructuralismo e historia, La Laguna, Ediciones de la Universidad, 1958, págs. 106-199.

43 Hídem. pág. 107.

At Op. cit, pág. 379

45 "Consideraciones sobre la formación léxica», en Serta Philologia F. Lázaro Carreter, I, Estudios de linginistica y lengua literaria, Madrid, Cátedra, 1983, págs. 11-15, en especial pág. 13.

46 «Forma y función de los interfijos», Revista Española de Lingiïistica, 16-2, 1986, págs. 381395.

47 Lingüistica general, op. cit., pág. 109.

*k Cir. Fernando Lázaro Mora, «Morfología de los sufijos diminutivos -ito(a), -ico(a), -illo(a)», Verba, 4, 1977, págs. 115-125, especialmente pág. 125.

4' Véanso Miguel A. Rebollo Torío, «En torno a los infijos», Anuario de Estudios Filológicos, VII, 1984, pág. 312 y 315 y Méndez-Dosuna y Carmen Pensado, art. cit.

51) Eugenio Martíncz Celdrán, «En torno a los conceptos de interfijo e infijo en español», Revista Española de Ling̈̈̈ística, 8-2, 1978, págs. 447-460.

51 «Sufijación y derivación sulijal: sentido y forma», en Soledad Varela Ortega (ed.), La fornación de palabras, sp. cit., págs. 119-161.

52. llídem, pág. 147 
El empleo de la interfijación en determinados discursos, como el periodístico, que incluye a su vez una importante heterogeniedad de códigos, puede venir dado por la búsqueda del alargamiento de determinados vocablos, en un intento de conseguir la acentuación esdrújula, como indica José Portolés ${ }^{53}$, quien determina, por otra parte, su función en el español ${ }^{54}$ mediante el establecimiento de seis principios:

a) El interfijo pertenece a la morfología derivativa.

b) El interfijo debe aparecer entre la base y el sufijo o la terminación verbal.

c) El interfijo es átono.

d) No son interfijos los sufijos que pertenecen a cadenas sufijales.

c) Debemos distinguir la interfijación de la estereotipia.

i) No son interfijos los segmentos que, formando parte de extranjerismos o de voces latinas, no sirvan o hayan servido para la creación léxica en nuestra lengua.

En cuanto a la parasíntesis, se suele afirmar tradicionalmente que aparece en los casos en los que actúan simultáneamente los afijos antepuestos y pospuestos. Así, la Academia ${ }^{55}$ afirma que en estas formaciones «se dan de una manera solidaria derivación y composición, sin que la palabra central, que no es sufijo ni prefijo [...] participe más de la una que de la otra». En parecidos términos se refirieron Arsène Darmesteter ${ }^{56}$, José Alemany ${ }^{57}$ o Ramón Menéndez Pidal ${ }^{58}$, aunque éste último empleó un criterio más restringido:

Los compuestos de prefijo y sufijo a la vez se llaman parasintéticos, de pará, que indica la yuxtaposición, y synthetikós, la síntesis de varios elementos que forman un término nuevo, como desalmado, donde sin que cxista un sustantivo desalma, ni un adjetivo almado, la reunión de los tres elementos forma un compuesto claro y expresivo.

Esta delimitación quedaría matizada sỉ nos fijamos en algunas formaciones verbales tradicionalmente no consideradas como parasintéticas, situadas en la derivación verbal mediata, que podrían considerarse como tales, a juicio de David

53 «Sobre los interfijos en español», Lingüística Española Actual, 10, 1988, págs. 153-169. Reeditado en Varela Ortega (ed.), La forntación de palabras, op. cit., págs. 339-359, especialmente pág. 346 .

54 Arr. cit., pígs. 341-342.

55 Esbozo de uma nueva gramática de la lengua española, op. cit., pág. 170.

56 Traité de la formation des mots composés dans la langue frangaises comparée aux autres langues romanes et cut latin, op. cit., pág. 96.

57 Tratado de la formación de palabras de la lengua castellana, op. cit., pág. 152.

58 Manual de gramática histórica española, Madrid, Espasa Calpe, $18^{a}$ ed., 1982. \$ 86.2., pág. 237. 
Serrano Dolader ${ }^{59}$. Los casos de derivación verbal mediata incluyen un constituyente afijo transcategorizador, al igual que las formas parasintéticas poseen sólo un formante que da lugar al cambio de categoría gramatical, mientras que los restantes modificarían semánticamente la forma verbal con la que se combinan, de ahí la coexistencia de parejas de vocablos en las que en uno de ellos aparece el término prefijado.

La propia definición de este «procedimiento misceláneo» ${ }^{6)}$, de mayor produclividad en español y francés que en las otras lenguas románicas, nos llevaría a hablar de "estructuración ternaria», frente a la «ramificación binaria» habitual $^{61}$, a no ser que nos refiramos a la presencia de una base derivada, por más que no se pueda hablar de existencia real ${ }^{62}$. En este sentido, autores como Fernando Lázaro Mora ${ }^{63}$, Luisa Blanco Rodríguez ${ }^{64}$ o, más recientemente, José Alberto Miranda ${ }^{65}$ hablan de la conveniencia de incluir los vocablos creados por parasíntesis entre las formas prefijadas, aunque como subgrupo especial.

En definitiva, todo aproximación a los diversos procedimientos de creación léxica en español debe huir de planteamientos dogmáticos. La realidad es, sin lugar a dudas, mucho más compleja de lo que parecen admitir los manuales. El análisis de la realidad lingüística a partir de corpora actuales nos aconseja rechazar generalizaciones y obrar con la deseada prudencia.

59. Las formaciones parasintéticas en español, Madrid, Arco/Libros, 1995, págs. $71-73$.

(it) Mervyn Franc Lang, op. cit., pág. 244.

(1) Véanse Mark Aronoff, op. cit. y Santiago Alcoba, «Los parasintéticos: constituyentes y estructura léxica», en Revista de la Sociedad Española de Lingüística, 17, 2, 1987, págs. 245-267.

62 Sergio Scalise, op. cit., especialmente pág. 170.

(13) «Sobre la parasíntesis en español», Dicenda, 5, 1986, págs. 221-235, especialmente pág. 235.

(i4 «Sobre la parasíntesis en español», Verba, 20, 1993, págs. 425-432, especialmente pág. 432.

op. cit., págs. 67-78. 